\title{
Antibiotic resistance of Escherichia coli isolated from uncomplicated UTI in general practice patients over a 10-year period
}



Received: 20 June 2019 / Accepted: 22 July 2019 / Published online: 22 August 2019

(C) The Author(s) 2019

\begin{abstract}
Recommendations of first choice antibiotic therapy need to be based on actual antibiotic susceptibility data. We determined the antibiotic susceptibility of E. coli in uncomplicated UTI among women and compared the results with 2004 and 2009. In 30 sentinel general practitioner practices of Nivel Primary Care database, urine samples were collected from women with symptoms of uncomplicated UTI. Patient characteristics, E. coli susceptibility, and ESBL production were analyzed. Six hundred eightynine urine samples were collected; $E$. coli was the most isolated uropathogen $(83 \%)$. Antibiotic susceptibility was stable over time except for ciprofloxacin (96\% in 2004, $97 \%$ in 2009 , and $94 \%$ in 2014; $P<0.05$ ). The susceptibility to co-amoxiclav was $88 \%$, $87 \%$, and $92 \%$ in 2004, 2009, and 2014, respectively. The prevalence of ESBL-producing E. coli increased from $0.1 \%$ in 2004 to $2.2 \%$ in $2014(P<0.05)$. Regional differences in antibiotic susceptibility for co-trimoxazole were found being the highest in the west $(88 \%)$ and the lowest in the north $(72 \%, P=0.021)$. Ciprofloxacin susceptibility was related to antibiotic use in the past 3 months (97\% no use versus $90 \%$ use, $P=0.002)$ and age $>70$ years $(P=0.005)$. In 2014, prescription of fosfomycin increased compared to 2009 (14.3\% versus 5.6\%) at the expense of co-amoxiclav, co-trimoxazole, and fluoroquinolones $(P<0.05)$. The susceptibility percentages to most antimicrobial agents tested were stable over 10 years' period although the prevalence of $E$. coli and ESBLs significantly increased. Performance of a survey with regular intervals is warranted.
\end{abstract}

Keywords Antibiotic resistance $\cdot$ Uncomplicated urine tract infections $\cdot$ Community-acquired $\cdot$ ESBLs

A. A. van Driel

a.a.vandriel@erasmusmc.nl

1 Department of Medical Microbiology \& Infectious Diseases, Erasmus University Medical Center, 's-Gravendijkwal 230, 3015 CE Rotterdam, The Netherlands

2 National Institute for Public Health and the Environment (RIVM), Antonie van Leeuwenhoeklaan 9, 3721 MA Bilthoven, The Netherlands

3 Department Infectious Disease Control, Municipal Public Health Service Rotterdam-Rijnmond (GGD Rotterdam), Rotterdam, The Netherlands

4 Department of Epidemiology, Erasmus Medical Center, 's-Gravendijkwal 230, 3015 CE Rotterdam, The Netherlands

5 Nivel Primary Care Database, Sentinel Practices, The Netherlands Institute for Health Services Research, Utrecht, The Netherlands

6 Department of Medical Microbiology, Maastricht University Medical Centre, Maastricht, The Netherlands

\section{Introduction}

Most antibiotics in the Netherlands prescribed by general practitioners (GPs) are for uncomplicated acute urinary tract infections (UTI) in women [1,2]. Escherichia coli (E. coli) is the most frequently isolated microorganism, in up to $80 \%$ of UTIs [3, 4]. Different studies report increased resistance of E. coli in UTI, especially to beta-lactam antibiotics and fluoroquinolones alone or in combination [5, 6]. Although antibiotic resistance in the Netherlands is one of the lowest worldwide, the prevalence of resistant microorganisms has been increasing over time. Several studies describe an increasing prevalence of extended spectrum $\beta$-lactamase (ESBL)producing Gram-negative rods and other highly resistant microorganism (HRMO) in the general population [7-9]. In addition, a high prevalence of resistant microorganisms has been reported in specific populations such as travelers returning from South East Asia [10], immigrants and refugees [11, 12], and patients with hospital-replaced home treatment [13], as well as in livestock and agriculture [14-17]. Therefore, to make an optimal empiric choice, it is important to determine 
with regular time intervals the antibiotic susceptibility in populations commonly treated such as women with UTI.

For women with UTI, treatment guidelines are published by the Dutch College of General Practitioners (NHG). The choice of antimicrobial agents in the guidelines is based on national antimicrobial resistance (AMR) data published in Nethmap [8]. These data are derived from microbiological laboratories sending data to the National Institute for Public Health and the Environment. Yearly, this institute in close cooperation with the SWAB (Dutch Working group on Antibiotic policy) reports national data on antibiotic consumption and resistance in humans and animals in Nethmap and MARAN, respectively [8]; based on the NHG guideline, GPs should only submit urine for culture after failure of first-line therapy [18]. However, antimicrobial resistance of uropathogens isolated after therapy failure is not representative for resistance rates in patients who were successfully treated. Since NHG guidelines for treatment of UTIs should be based on the latter population, we determined the AMR among women with complaints of an acute uncomplicated UTI visiting their GPs. Additionally, to determine trends in susceptibility, AMR data of 2014 were compared with the data collected in a similar population in 2004 and 2009 [19, 20].

\section{Patients and methods}

\section{Patients}

From January 2014 to January 2015, all women of 11 years and older with symptoms of dysuria, strangury, or urinary frequency visiting 30 sentinel GP practices participating in Nivel Primary Care Database were included [21]. This GP network is nationally representative by regional distribution, population density, practice features, GP, and patient characteristics [21]. Exclusion criteria were symptoms of complicated UTI, fever $>38^{\circ} \mathrm{C}$, pregnancy, diabetes mellitus, urological or nephrological problems, or immunodeficiency of any kind, as were also antibiotic use and an episode of recurrent UTI in the past 4 weeks.

To avoid bias concerning age, region, or medical history of the patient, a maximum of 25 samples from any GP practice was included during the study period.

Antibiotic prescription and UTI treatment history in the past 3 months were recorded. A urine dipslide (Uriline, 56508; BioMérieux, Plainview, NY USA) was inoculated according to the manufacturer's instructions and sent for analysis to the Centre for Infectious Diseases Research, Diagnostics and laboratory Surveillance (IDS) of the National Institute for Public health and the Environment (RIVM) in the Netherlands.

\section{Ethics approval and consent to participate}

For patient-derived data from the NIVEL-PCD, ethics approval via an METC was not needed, as explained in the "Privacy statement NIVEL PCD": Dutch law allows the use of electronic health records for research purposes under certain conditions. According to this legislation, neither obtaining informed consent from patients nor approval of a medical ethics committee is obligatory for this type of observational studies containing no directly identifiable data (Dutch Civil Law, Article 7:458; http:// www.dutchcivillaw.com/ civilcodebook077.htm). This study has been approved by the applicable governance bodies of NIVEL Primary Care Database under nr. NZR00316.012.

\section{Identification of the uropathogens and antibiotic susceptibility testing}

Bacterial growth on the dipslide was considered positive at $\geq$ $10^{5} \mathrm{cfu} / \mathrm{mL}$. Growth of two or more bacterial species was considered as contaminated and excluded. For identification of the uropathogens, MALDI-TOF MS (MALDI Biotyper 3.0 van Bruker Daltonik GmbH, Bremen, Germany) was used. The isolated microorganisms were stored at $-20{ }^{\circ} \mathrm{C}$ in peptone/glycerol $(30 \% \mathrm{w} / \mathrm{v})$.

The antibiotic susceptibility of the isolates was performed by disk diffusion according to the EUCAST criteria version 4.0 valid from Jan 1, 2014 as were the breakpoints of susceptibility. The following antibiotics were tested: amoxicillin $(10 \mu \mathrm{g})$, co-amoxiclav $(20 / 10 \mu \mathrm{g})$, trimethoprim $(5 \mu \mathrm{g})$, cotrimoxazole $(1.25 / 23.75 \mu \mathrm{g})$, ciprofloxacin $(5 \mu \mathrm{g})$ nitrofurantoin $(100 \mu \mathrm{g})$, and fosfomycin $(200 \mu \mathrm{g})$. Escherichia coli ATCC 35218 and ATCC 25922 were used as control strains; breakpoints of susceptibility were according to the EUCAST guidelines (http://www.eucast.org/clinical breakpoints/). The susceptibility of fosfomycin was tested using the CLSI guidelines [22]. For detection of ESBLproducing bacteria, putative colonies were streaked on ChromID ESBL agar (Biomerieux) and confirmation of ESBL production was performed according to the guideline of the Dutch Society of Medical Microbiology (NVMM) [23].

\section{Comparison with the 2004 and 2009 data}

The GP network, patient population, and methods were comparable to those described in the 2004 and 2009 studies, as were the criteria for inclusion and exclusion of patients. The microbiological analysis was performed in another laboratory using the same methods as described for the 2004 and 2009 studies $[19,20,22,23]$. The difference with the studies of 2004 and 2009 was the cutoff to define a UTI using a colony count of $10^{5} \mathrm{cfu} / \mathrm{mL}$ in the present study instead of $10^{3} \mathrm{cfu} / \mathrm{mL}$ in the previous ones. The EUCAST version used was version 
1.0 tentative for the period 2002-2009 and version 1.2 valid from December 2010 in the previous studies and EUCAST version 4.0 valid from January 2014 in the present one (http:// www.eucast.org/clinical_breakpoints/).

\section{Regional differences}

To analyze regional differences, we used the regional distribution as used by Nivel [21]: North (provinces Groningen, Friesland, and Drenthe), East (Overijssel, Gelderland, and Flevoland), West (Utrecht, North-Holland, and SouthHolland), and South (Zeeland, North-Brabant, and Limburg) [21].

\section{Statistics}

For the statistical analysis, SPSS 23.0 was used. The $X^{2}$ test was used to test the significance of associations within the data.

\section{Results}

\section{Baseline characteristics}

During the study period, 689 urine samples were collected, of which $535(78 \%)$ were considered positive, 117 (17\%) negative, and 37 (5\%) were excluded because two or more bacteria species were isolated. The median age of the total group of all women was 57 years (range 11-101 years). Antibiotic use in the past 3 months was the lowest in the age group 11-20 years (17\%) and increased to $46 \%$ in the age group of 70 years and older. E. coli was the most frequently detected uropathogen ( $83 \%)$, followed by Klebsiella pneumonia (5\%) and Klebsiella oxytoca $(1.5 \%)$.

\section{Antibiotic susceptibility of $E$. coli}

Table 1 shows the susceptibility of $E$. coli in relation to three determinants, i.e., antibiotic use in the past 3 months, age, and region. Overall, the susceptibility ranges from $66 \%$ for amoxicillin to $94 \%$ for ciprofloxacin and nearly $100 \%$ for both nitrofurantoin and fosfomycin. For the various antibiotics, only three statistically significant associations were found between susceptibility and any of the three determinants. For co-trimoxazole, the association with region was significant: highest susceptibility in the west (88\%) and lowest in the north (72\%, $P=0.021)$. For ciprofloxacin, the associations with both previous antibiotic use and age were significant: less susceptibility when previous antibiotic use (90\% vs $97 \%$ ) $(P=0.002)$ and age $>71(88 \%)(P=0.005)$. The association with region could not be tested for ciprofloxacin (violation of chi-square test assumptions). Only 26,3 , and 2 isolates were resistant to ciprofloxacin, nitrofurantoin, and fosfomycin, respectively.

Of the $10 \mathrm{ESBL}$ (2.2\%)-positive isolates, nine were in the age group 21 to 70 years, eight of them were from the Eastern region.

\section{Comparison with the survey of 2004 and 2009}

The prevalence of $E$. coli isolates increased from $64 \%$ $(1013 / 1583)$ in 2004 to $72 \%(350 / 487)$ in 2009 [23], and to $83 \%(445 / 535)$ in $2014(2004-2014, P<0.05)$. No significant differences in prevalence were observed for the other isolated uropathogens (data not shown).

\section{Antibiotic prescriptions in 2009 and 2014}

There was a significant difference in empiric antibiotic prescriptions between 2009 and $2014(P<0.05)$. The empirical prescribing of nitrofurantoin and fosfomycin increased, whereas the prescribing of the other antibiotics decreased (Table 2). The antibiotic use between 1999 and 2014 fluctuated between 10 and $11 \mathrm{DDD} / 1000$ inhabitant-days [24].

In 2014, empirical antibiotic treatment was prescribed to 424 of the 689 patients (61.5\%), and unknown in $70(10.2 \%)$ patients. The most frequently prescribed antibiotic was nitrofurantoin $(n=293,69 \%)$, followed by fosfomycin $(n=$ $60,14 \%)$ and ciprofloxacin $(n=25,6 \%)$; the last two antibiotics were especially used in the elderly ( $>51$ years), $38 \%$ and $16 \%$, respectively.

\section{AMR from 2004 to 2014}

Table 3 compares antibiotic susceptibilities of E. coli over time. The susceptibility to co-amoxiclav was in the 2004 study $88 \%$ and in $200987 \%$ compared to $92 \%$ in 2014 . The susceptibility for ciprofloxacin decreased significantly from $97 \%$ in 2009 to $94 \%$ in 2014 ( $X^{2}$ test; $P<0.05$ ), but the decrease from 2004 (96\%) to 2014 was not significant $\left(X^{2}\right.$ test; $\left.P=0.10\right)$. No other differences in susceptibility to the other agents over time were found.

The prevalence of ESBL-producing $E$. coli increased over time from $0.1 \%(1 / 1378)$ in 2004 , to $1 \%(5 / 489)$ in 2009 and to $2.2 \%(10 / 445)$ in 2014 . The numbers involved do not allow for testing the significance of this increase.

\section{Discussion}

In this study, we demonstrate that AMR did not increase over the 10-year study period except the resistance to ciprofloxacin and the prevalence of ESBL-producing $E$. coli. These results are remarkable in this time of worldwide concern on the increase in prevalence of antibiotic resistance [5, 6]. We also 
Table 1 Antibiotic susceptibility of E. coli according to previous antibiotic use, age, and region

\begin{tabular}{|c|c|c|c|c|c|c|}
\hline Amoxicillin & $\begin{array}{l}\text { Co- } \\
\text { amoxiclav }\end{array}$ & Trimethoprim & $\begin{array}{l}\text { Co- } \\
\text { trimoxazole* }\end{array}$ & Ciprofloxacin $* *$ & Nitrofurantoin $* * *$ & Fosfomycin $* * *$ \\
\hline
\end{tabular}

\begin{tabular}{|c|c|c|c|c|c|c|c|}
\hline Yes $(N=144)$ & $87(60 \%)$ & $131(91 \%)$ & $108(75 \%)$ & $111(77 \%)$ & $129(90 \%)$ & $142(99 \%)$ & $142(99 \%)$ \\
\hline No $(N=282)$ & $196(70 \%)$ & $261(93 \%)$ & $228(81 \%)$ & $235(83 \%)$ & $273(97 \%)$ & $281(100 \%)$ & $282(100 \%)$ \\
\hline Total $(N=426)^{\mathrm{i}}$ & $283(66 \%)$ & $392(92 \%)$ & $336(79 \%)$ & $346(81 \%)$ & $402(94 \%)$ & $423(99 \%)$ & $424(100 \%)$ \\
\hline \multicolumn{8}{|l|}{ Age } \\
\hline $11-20(N=28)$ & $19(68 \%)$ & $25(89 \%)$ & $22(79 \%)$ & $23(82 \%)$ & $26(93 \%)$ & $28(100 \%)$ & $28(100 \%)$ \\
\hline $21-50(N=136)$ & $88(65 \%)$ & $129(95 \%)$ & $107(79 \%)$ & $112(82 \%)$ & $131(96 \%)$ & $136(100 \%)$ & $136(100 \%)$ \\
\hline $51-70(N=155)$ & $107(69 \%)$ & $143(92 \%)$ & $125(81 \%)$ & $127(82 \%)$ & $151(97 \%)$ & $153(99 \%)$ & $154(99 \%)$ \\
\hline$>70(N=126)$ & $79(63 \%)$ & $110(87 \%)$ & $99(79 \%)$ & $101(80 \%)$ & $111(88 \%)$ & $125(99 \%)$ & $125(99 \%)$ \\
\hline Total $(N=445)$ & $293(66 \%)$ & $407(91 \%)$ & $353(79 \%)$ & $363(82 \%)$ & $419(94 \%)$ & $442(99 \%)$ & $443(100 \%)$ \\
\hline \multicolumn{8}{|l|}{ Region } \\
\hline North $(N=82)$ & $53(65 \%)$ & $73(89 \%)$ & $59(72 \%)$ & $59(72 \%)$ & $72(88 \%)$ & $81(99 \%)$ & $82(100 \%)$ \\
\hline East $(N=71)$ & $50(70 \%)$ & $64(90 \%)$ & $55(77 \%)$ & $56(79 \%)$ & $64(90 \%)$ & $70(99 \%)$ & $71(100 \%)$ \\
\hline West $(N=184)$ & $125(68 \%)$ & $169(92 \%)$ & $153(83 \%)$ & $161(88 \%)$ & $178(97 \%)$ & $184(100 \%)$ & $182(99 \%)$ \\
\hline South $(N=108)$ & $65(60 \%)$ & $101(94 \%)$ & $86(80 \%)$ & $87(81 \%)$ & $105(97 \%)$ & $107(99 \%)$ & $108(100 \%)$ \\
\hline Total $(N=445)$ & $293(66 \%)$ & $407(91 \%)$ & $353(79 \%)$ & $363(82 \%)$ & $419(94 \%)$ & $442(99 \%)$ & $443(100 \%)$ \\
\hline
\end{tabular}

${ }^{\mathrm{i}}$ In the case of antibiotic use in the last 3 months, 19 cases were unknown

*Association between susceptibility and region $(P=0.021)$

**Associations between susceptibility and both previous antibiotic use $(P=0.002)$ and age $(P=0.005)$. For region, testing is inappropriate due to small numbers

***Testing is inappropriate due to small numbers

showed that the prevalence of $E$. coli isolated from urine significantly increased in this time period and that fosfomycin was more frequently prescribed at the expense of co-amoxiclav, co-trimoxazole, and fluoroquinolones.

In contrast to the global tendency of increasing AMR [25], we showed only small changes in antibiotic susceptibility over a 10-year time period. Both in Europe and on other continents, AMR has been increasing in bacteria causing UTIs [5, 26-28]. The Netherlands has always reported relatively low AMR rates and prudent antibiotic use [29]. Antibiotic consumption has been directly related to AMR and the low antibiotic use in the Netherlands may be an explanation for the stable AMR [30-32]. It should be noted that the cultures were taken from community-dwelling females with uncomplicated UTIs and a presumed low antibiotic use and pressure.

The susceptibility of E. coli to co-amoxiclav increased from $88 \%$ and $87 \%$ in the 2004 and 2009 studies to $92 \%$ in the present one. In the last study, the EUCAST criteria version 4.0 valid from January 2014 was used, whereas the two other studies used the version 1.2. The main difference is the breakpoint for susceptibility for co-amoxyclav being $>$ $16 \mathrm{~mm}$ for all infections according to the version 1.2 and > $15 \mathrm{~mm}$ for UTI only is mentioned in the 4.0 version. The version 1.2 does not mention the criterium "UTI only"; in the 4.0 version, the breakpoint for all infections is $>18 \mathrm{~mm}$. Due to the different breakpoints used and depending on the type of infections, it is difficult to assess whether the increase in susceptibility is a real increase of just a virtual one. In other European countries, a decrease of susceptibility has been described [26]. In Ireland, the susceptibility of $E$. coli to coamoxiclav decreased from $90 \%$ in 2005 to $80 \%$ in 2014 in community-dwelling patients with UTI [27]. Also in Germany, co-amoxiclav susceptibility decreased from $92 \%$ in 2014 to $75 \%$ in 2017 [28].

The decreased susceptibility of $E$. coli to ciprofloxacin was in line with other studies [26-28]. In the EC0-SENS study, a significant increase of resistance to ciprofloxacin from 2000 to 2014 was observed in different countries: in Germany from 2.2 to $20.2 \%$, in Spain from 14.7 to $30.8 \%$, in Sweden from 0.0 to $7.3 \%$, and in the UK from 0.6 to $15.3 \%$ [26]. In Ireland, resistance to ciprofloxacin increased from 5\% in 2005 to $11.4 \%$ in 2014 [27]. An average increase in resistance per year of $0.40 \%$ and $0.26 \%$ was found both in community-dwelling and hospitalized patients, respectively [28]. According to the Dutch NHG guidelines, ciprofloxacin is a last resort drug and we showed that prescription rates decreased from $14 \%$ in $2004,10 \%$ in 2009 , to $5.9 \%$ in 2014 [18]. However, only a small effect on susceptibility percentages could be demonstrated; the E. coli susceptibility decreased from $96 \%$ in 2004 to $94 \%$ in 2014 (Table 3).

The rise in prevalence over time of $E$. coli was a remarkable finding. Although the microbiological analysis of our last 
Table 2 Number (\%) of empiric antibiotic prescriptions in the 2009 and 2014 surveys

\begin{tabular}{lll}
\hline & $\begin{array}{l}2009 \\
N=719\end{array}$ & $\begin{array}{l}2014 \\
N=419\end{array}$ \\
\hline Amoxicillin, $N(\%)$ & $13(1.8)$ & $2(0.5)$ \\
Co-amoxiclav, $N(\%)$ & $54(7.5)$ & $18(4.3)$ \\
Trimethoprim, $N(\%)$ & $38(5.3)$ & $14(3.3)$ \\
Co-trimoxazole, $N(\%)$ & $27(3.8)$ & $3(0.7)$ \\
Fluoroquinolones, $N(\%)$ & $75(10.4)$ & $29(6.9)$ \\
Nitrofurantoin, $N(\%)$ & $472(65.6)$ & $293(69.9)$ \\
Fosfomycin, $N(\%)$ & $40(5.6)$ & $60(14.3)$ \\
\hline
\end{tabular}

Fluoroquinolones; ciprofloxacin, norfloxacin

Azithromycin $(n=3)$ prescription excluded

Unknown $(n=2)$ in 2014

$\left(X_{2}\right.$ test $\left.P<0.05\right)$

survey was performed in another laboratory, the methods were comparable. The 2009 survey showed already a significant increase in prevalence of $E$. coli compared to 2004 [20]. The prevalence of $E$. coli in UTI ranged from 76.7 to $84 \%$ in different studies [27, 32, 33]. Cullen et al. also described an increase of $E$. coli in an 11-year period of uncomplicated UTI in community patients including fluctuation over time [33]. Different explanations were described in the literature, such as rise in global temperature, seasonal peaks, and increasing age of women with symptoms of UTI [34-36]. In this study, we included patients during 6 months and did not observe influences of these seasons or age for the percentage of $E$. coli isolates.

In Belgium, Heytens et al. found in a 20-year survey from 1995 to 2015 a higher percentage of $E$. coli in uncomplicated UTI in post-menopausal women $>55$ years of age compared to the age group of $18-54$ years, $89.9 \%$ versus $78.4 \%$, respectively [36]. Although the mean age in our study was 53.5 years and $57 \%$ was 51 years or older, the prevalence of $E$. coli in the

Table 3 Total E. coli susceptibility (\%) in 2004 (Nys), 2009 (den Heijer), and 2014

\begin{tabular}{llll}
\hline & 2004 & 2009 & 2014 \\
& $N=1378$ & $N=489$ & $N=445$ \\
\hline Amoxicillin & $923(67)$ & $323(66)$ & $293(66)$ \\
Co-amoxiclav & $1213(88)$ & $425(87)$ & $407(92)$ \\
Trimethoprim & $1061(77)$ & $396(81)$ & $353(79)$ \\
Co-trimoxazole & $1102(80)$ & $411(84)$ & $363(82)$ \\
Ciprofloxacin* & $1323(96)$ & $474(97)$ & $419(94)$ \\
Nitrofurantoin** & $1364(99)$ & $489(100)$ & $442(99)$ \\
Fosfomycin** & $1364(99)$ & $489(100)$ & $443(99)$ \\
\hline
\end{tabular}

* Indicates a significant decreased antibiotic susceptibility between 2009 and 2014 for ciprofloxacin $\left(X^{2}\right.$ test; $\left.P<0.05\right)$

**Numbers too low for chi-squared test age group 51 years and older was comparable to the younger age group ( $82 \%$ versus $84 \%$, respectively).

Other uropathogens such as $K$. pneumonia and $K$. oxytoca were isolated less frequently. Risk factors for uropathogens other than E. coli, like recurrent UTI, pregnancy, intensive care hospitalization, presence of catheters, gender, age, and diabetes mellitus, were exclusion criteria in our study except age and gender [36, 37].

The regional differences in susceptibility of $E$. coli (Table 1) were in contrast to the regional antibiotic prescription of these agents (Table 2). The Northern and Eastern regions are both adjacent to Germany, where, as shown in the updated ECO-SENS study, resistance to ciprofloxacin increased from 2.2 to $20.2 \%$, and trimethoprim from 22.5 to $36.8 \%$ from 2000 to 2014 [26]. Social and economic traffic between the regions and Germany is common [38] and geographical boundaries are not recognized by microorganisms [39]. However, no data is available of E. coli susceptibility in uncomplicated UTI in the community in the cross-border region. We found only limited regional data on antibiotic resistance in Belgium or in Germany. The only available numbers we found in Belgium were described in the relatively small study of De Backer (2008) in the region Gent with 187 patients [40]. He described in his study from 1996 to 2006 a stable prevalence of antibiotic susceptibility in urinary isolates, i.e., a susceptibility of 83.3 to $86 \%$ for co-trimoxazole, versus $86 \%$ in the South and $83 \%$ in the Western part of the Netherlands (Den Heijer 2009). Van den Donk et al. compared the prevalence of resistance in the cross-border region between Belgium, Germany, and the Netherlands among general practitioners, nursing homes, and ICU isolates and found a significant difference in prevalence of co-amoxiclav and ciprofloxacin resistance among all E. coli isolated between the Netherlands and Belgium, i.e., $27 \%$ versus $21 \%$, and $23 \%$ and $16 \%$, respectively. No significant differences with Germany were reported [41].

We found a regional difference in prevalence of ESBLpositive isolates, where 8 out of 10 isolates all in the age group of over 51 were from the Eastern region, close to the border of Germany. The ECO-SENS study in 2014 reported an ESBL incidence of $10.5 \%$ [26]. Van den Donk et al. (2012) showed a cross-border spread of E. coli ST131 and CTX-M type ESBLs and a similar prevalence of resistant $E$. coli in the Euregio Meuse Rhine [42]. A recent study found the same ESBL CTXM15 genotype in cross-border hospitals in the Northern part of the Netherlands and in Germany whereas in community isolates from the Netherlands, CTXM1 was found. The results of this small study suggested cross-border spread in clinical isolates. As no data was available from German community strains, no conclusion could be drawn concerning possible cross-border spread in the community [43]. 
The prevalence of ESBL-positive $E$. coli isolates increased from $0.1 \%$ in 2004 to $1.0 \%$ in 2009 and $2.2 \%$ in 2014 . Several reports also mentioned an increase in ESBL-producing $E$. coli in community-acquired urinary tract infections. In Germany, an increase was found, from 1.2 to $4.8 \%$ in 8 years' time [26], and more than $12 \%$ in a 10 -year period in Ireland [27]. Of the different risk factors described, such as recurrent UTI in the past year, (recent) use of $\beta$ lactam antibiotics or fluoroquinolones, and traveling to Asia, Middle East, and Africa [10, 44], we only had information for recurrent UTI.

The increase in nitrofurantoin and fosfomycin as empirical prescription by the participating GPs was in line with the first and second choice of antibiotic treatment of uncomplicated UTI according to the NHG guidelines [18]. In addition, the prescription of fluoroquinolones, co-trimoxazole, and coamoxiclav decreased significantly. The increase of fosfomycin prescription was in line with the alteration from third to second preference in 2013 of the national guideline. These data underscore the adherence of GPs to the national guidelines and indicate that national guidelines are valuable in antibiotic stewardship [45].

Although fosfomycin shows promising results of low resistance in UTI isolates [46] recently, a few studies describe less clinical efficacy $[47,48]$. Based on the literature and the NHG guidelines, our recommendation is still nitrofurantoin as first choice, followed by fosfomycin and trimethoprim as third place if the isolated pathogen is susceptible. When more clinical studies become available concerning the (decreased) clinical efficacy of fosfomycin, the NHG guidelines might revise the recommendations.

\section{Strengths and limitations}

The strength of our study is the national coverage, because the participating general practices are nationally representative for age, gender, regional distribution, and population density [21]. This enables us to compare (regional) differences in antibiotic resistance of uropathogenic $E$. coli over time and to evaluate whether the prescriptions of the GPs are in line with the recommendations of the NHG guideline for the treatment of uncomplicated UTI. The data we collected in our study is essential for the setup of guidelines for the treatment of uncomplicated UTI. Data in Nethmap are from patients after therapy failure and not representative for successfully treated patients and not suitable for the NHG guidelines [18].

A limitation of our study is the limited information regarding lifestyle, known risk factors, like co-morbidity, hospitalization, reinfection, or previous antibiotic use. More detailed information as to patient and environmental characteristics is recommended in the next survey. Also, our study is only representative for the group of healthy women. Men and children should be further investigated in a next survey to complete national guidelines for GPs in treatment of UTI.

In conclusion, the susceptibility percentages of $E$. coli to most antimicrobial agents isolated from uncomplicated UTI among women were stable in the Netherlands over 10 years' time, although the prevalence of $E$. coli and ESBL-producing $E$. coli increased. These findings suggest that performing the survey at a regular interval is warranted. The GPs' empirical prescription treatment was in line with the recommendations of the national NHG guidelines.

Acknowledgments We thank the laboratory technicians and Max Heck, RIVM-IDS for performing the urine cultures and antibiotic susceptibility measurements.

We are grateful to all participating sentinel general practitioners of the Nivel Primary Care Database for their cooperation.

Funding This work was supported by the Dutch Foundation of the Working Part on Antibiotic Policy (SWAB).

\section{Compliance with ethical standards}

This study has been approved by the applicable governance bodies of NIVEL Primary Care Database under nr. NZR00316.012.

Conflict of interest The authors declare that they have no conflict of interest.

Open Access This article is distributed under the terms of the Creative Commons Attribution 4.0 International License (http:// creativecommons.org/licenses/by/4.0/), which permits unrestricted use, distribution, and reproduction in any medium, provided you give appropriate credit to the original author(s) and the source, provide a link to the Creative Commons license, and indicate if changes were made.

\section{References}

1. NIVEL (2004) De tweede nationale studie naar ziekten en verrichtingen in de huisartsenpraktijk. https://www.nivel.nl/sites/ default/files/bestanden/ns2_rapport1.pdf. Accessed 4 March 2019

2. NIVEL (2014) Zorg door de huisarts. https://www.nivel.nl/nl/nzr/ top-20-diagnoses-bij-contacten-met-de-huisarts. Accessed 6 March 2018

3. Schito GC, Naber KG, Botto H et al (2009) The ARESC study: an international survey on the antimicrobial resistance of pathogens involved in uncomplicated urinary tract infections. Int $\mathrm{J}$ Antimicrob Agents 34:407-413

4. Allocati N, Masulli M, Alexeyev MF et al (2013) Escherichia coli in Europe: an overview. Int J Environ Res Public Health 10(12): 6235-6254

5. The European Antimicrobial Resistance Surveillance Network (EARSNET) (2017) Annual Report of the European Antimicrobial Resistance Surveillance Network; Stockholm, Sweden

6. Glasner C, Albiger B, Buist G, et al (2013) Carbapenemaseproducing Enterobacteriaceae in Europe: a survey among national experts from 39 countries. European Survey on CarbapenemaseProducing Enterobacteriaceae (EuSCAPE) Working Group. Euro Surveill July 2013 11; 18(28) 
7. Huijbers PMC, de Kraker M, Graat EAM et al (2013) Prevalence of extended-spectrum $\beta$-lactamase-producing Enterobacteriaceae in humans living in municipalities with high and low broiler density. Clin Microbiol Infect 19(6):E256-E259

8. NethMap 2017: Consumption of antimicrobial agents and antimicrobial resistance among medically important bacteria in the Netherlands (2017). Bilthoven: Rijksinstituut voor Volksgezondheid en Milieu (RIVM); https://doi.org/10.21945/ RIVM-2017-0056

9. Reuland EA, Naiemi NA, Kaiser AM et al (2016) Prevalence and risk factors for carriage of ESBL-producing Enterobacteriaceae in Amsterdam. J Antimicrob Chemother 71(4):1076-1082

10. Arcilla MS, van Hattem JM, Haverkate MR et al (2017) Import and spread of extended-spectrum $\beta$-lactamase-producing Enterobacteriaceae by international travellers (COMBAT study): a prospective, multicentre cohort study. Lancet Infect 17(1):78-85

11. Ahmed SS, Alp E, Ulu-Kilic A et al (2016) Spread of carbapenemresistant international clones of Acinetobacter baumannii in Turkey and Azerbaijan: a collaborative study. Eur J Clin Microbiol Infect Dis $35: 1463-1468$

12. Nellums LB, Thompson H, Holmes A et al (2018) Antimicrobial resistance among migrants in Europe: a systematic review and meta-analysis. Lancet Infect Dis 18:796-811

13. ECDC (2011) Risk assessment on the spread of carbapenemaseproducing Enterobacteriaceae (CPE), through patient transfer between healthcare facilities, with special emphasis on cross-border transfer. ECDC, Stockholm 13 September

14. Leverstein-van Hall MA, Dierikx CM, Cohen Stuart J et al (2011) Dutch patients, retail chicken meat and poultry share the same ESBL genes, plasmids and strains. Clin Microbiol Infect 17:873880

15. Huijbers PM, Blaak H, De Jong MC et al (2015) Role of the environment in the transmission of antimicrobial resistance to humans: a review. Environ Sci Technol 49:11993-12004

16. Blaak H, De Kruijf P, Hamidjaja RA et al (2014) Prevalence and characteristics of ESBL-producing E. coli in Dutch recreational waters influenced by wastewater treatment plants. Vet Microbiol 171:448-459

17. Reuland EA, Al Naiemi N, Raadsen SA et al (2014) Prevalence of ESBL-producing Enterobacteriaceae in raw vegetables. Eur J Clin Microbiol Infect Dis 33:1843-1846

18. Van Pinxteren B, Knottnerus BJ, Geerlings SE et al (2013) NHGStandaard Urineweginfecties (derde herziening). Huisarts Wet 56(6):270-280

19. Nys S, van Merode T, Bartelds AI et al (2006) Urinary tract infections in general practice patients: diagnostic tests versus bacteriological culture. J Antimicrob Chemother 57(5):955-958

20. den Heijer CD, Donker GA, Maes J et al (2010) Antibiotic susceptibility of unselected uropathogenic Escherichia coli from female Dutch general practice patients: a comparison of two surveys with a 5 year interval. J Antimicrob Chemother 65(10):2128-2133

21. Donker G. (2011) Continuous Morbidity Registration Dutch Sentinel General Practice Network. https://www.nivel.nl/sites/ default/files/bestanden/Rapport-Peilstations-2011-engels.pdf. Accessed 27 Dec 2017

22. Clinical and Laboratory Standards Institute (2005) Performance standards for antimicrobial susceptibility testing: fifteenth informational supplement M100-S15. CLSI, Wayne

23. NVMM (2012), NVMM-richtlijn voor screening en confirmatie van extended-spectrum beta-lactamases (ESBL's) in Enterobacteriaceae. https://www.nvmm.nl/media/1051/2012 hrmo_mrsa_esbl.pdf (last revision 2012)

24. Nethmap (2015) https://www.swab.nl/swab/cms3.nsf/uploads/ 4F5A0D8E6F0DD139C1257E6E0051833 A/\$FILE/ NethmapMaran2015_webversie.pdf. Accessed 3 May 2017
25. WHO (2014) Antimicrobial resistance global report on surveillance. www.who.int/iris/bitstream/10665/112642/1/ 9789241564748 eng.pdf. Accessed 15 Dec 2017

26. Kahlmeter G, Åhman J, Matuschek E (2015) Antimicrobial resistance of Escherichia coli causing uncomplicated urinary tract infections: a European update for 2014 and comparison with 2000 and 2008. Infect Dis Ther 4(4):417-423

27. Stapleton PJ, Lundon DJ, McWade R et al (2017) Antibiotic resistance patterns of Escherichia coli urinary isolates and comparison with antibiotic consumption data over 10 years, 2005-2014. Ir J Med Sci 186(3):733-741

28. Seitz M, Stief C, Waidelich R (2017) Local epidemiology and resistance profiles in acute uncomplicated cystitis (AUC) in women: a prospective cohort study in an urban urological ambulatory setting. BMC Infect Dis 16(17(1)):685

29. Nethmap (2014) http://www.swab.nl/swab/cms3.nsf/uploads/ 4F5A0D8E6F0DD139C1257E6E0051833 A/\$FILE/ NethmapMaran2015_webversie.pdf

30. Versporten A, Bolokhovets G, Ghazaryan L et al (2014) On behalf of the WHO/Europe-ESAC Project group. Antibiotic use in eastern Europe: a cross sectional database study in coordination with the WHO regional Office for Europe. Lancet Infect Dis 14:381-387

31. Costelloe C, Metcalfe C, Lovering A et al (2010) Effect of antibiotic prescribing in primary care on antimicrobial resistance in individual patients: systematic review and meta-analysis. BMJ 18:340

32. Søraas A, Sundsfjord A, Sandven I et al (2013) Risk factors for community-acquired urinary tract infections caused by ESBLproducing enterobacteriaceae-a case-control study in a low prevalence country. PLoS One 23(8(7)):e69581

33. Cullen IM, Manecksha RP, McCullagh E et al (2012) The changing pattern of antimicrobial resistance within 42,033 Escherichia coli isolates from nosocomial, community and urology patient-specific urinary tract infections, Dublin, 1999-2009. BJU Int 109(8):11981206

34. European Environment Agency, Global and European Temperature (CSI 012/CLIM 001) (2012) http://www.eea.europa.eu.eur.idm. oclc.org/data-and-maps/indicators/global-and-europeantemperature/global-and-european-temperature-assessment-4 (11 March 2012, date last accessed)

35. Al-Hasan M, Lahr BD, Eckel-passow JE et al (2009) Seasonal variation in Escherichia coli bloodstream infection: a populationbased study. Clin Microbiol Infect 15(10):947-950

36. Heytens S, Boelens J, Claeys G et al (2017) Uropathogen distribution and antimicrobial susceptibility in uncomplicated cystitis in Belgium, a high antibiotics prescribing country: 20-year surveillance. Eur J Clin Microbiol Infect Dis 36(1):105-113

37. Azap OK, Arslan H, Serefhanoğlu K et al (2010) Risk factors for extended-spectrum beta-lactamase positivity in uropathogenic Escherichia coli isolated from community-acquired urinary tract infections. Clin Microbiol Infect 16(2):147-151

38. CBS (2016). https://www.cbs.nl/nl-nl/nieuws/2016/37/meerduitsers-pendelen-naar-nederland-dan-andersom.com

39. WHO (2001). http://www.who.int/drugresistance/WHO Global Strategy_English.pdf. Accessed 5 Sep 2018

40. De Backer D, Christiaens T, Heytens S et al (2008) Evolution of bacterial susceptibility pattern of Escherichia coli in uncomplicated urinary tract infections in a country with high antibiotic consumption: a comparison of two surveys with a 10 year interval. J Antimicrob Chemother 62(2):364-368

41. van der Donk C, van de Bovenkamp J, Bamelis H et al (2013) Prevalence and spread of multidrug-resistant Escherichia coli including ST131 in different patient populations in the Euroregion Meuse-Rhine. Future Microbiol 8(8):1027-1037

42. van der Donk CF, van de Bovenkamp JH, De Brauwer EI et al (2012) Antimicrobial resistance and spread of multi drug resistant 
Escherichia coli isolates collected from nine urology services in the Euregion Meuse-Rhine. PLoS One 7(10):e47707

43. Zhou X, García-Cobos S, Ruijs GJHM et al (2017) Epidemiology of extended-spectrum $\beta$-lactamase-producing E. coli and vancomycin-resistant enterococci in the northern Dutch-German cross-border region. Front Microbiol 8:1914

44. Linhares I, Raposo T, Rodrigues A et al (2013) Frequency and antimicrobial resistance patterns of bacteria implicated in community urinary tract infections: a ten-year surveillance study (20002009). BMC Infect Dis 18(13): 19

45. Butler CC, Francis N, Thomas-Jones E et al (2017) Variations in presentation, management, and patient outcomes of urinary tract infection: a prospective four-country primary care observational cohort study. Br J Gen Pract 67(665):e830-e841

46. Karlowsky JA, Denisuik AJ, Lagacé-Wiens PR et al (2014) In vitro activity of fosfomycin against Escherichia coli isolated from patients with urinary tract infections in Canada as part of the CANWARD surveillance study. Antimicrob Agents Chemother 58(2):1252-1256

47. Huttner A, Kowalczyk A, Turjeman A (2018) Effect of 5-day nitrofurantoin vs single-dose fosfomycin on clinical resolution of uncomplicated lower urinary tract infection in women: a randomized clinical trial. JAMA 319(17):1781-1789

48. Effect of 5-Day Nitrofurantoin vs Single-Dose Fosfomycin on Clinical Resolution of Uncomplicated Lower Urinary Tract Infection in Women: A Randomized Clinical Trial JAMA 319(17) April $2018: 1781-1789$

Publisher's note Springer Nature remains neutral with regard to jurisdictional claims in published maps and institutional affiliations. 